\title{
Optimal management of localized rectal cancer in older patients
}

Citation for published version (APA):

Bujko, K., Glynne-Jones, R., Papamichael, D., \& Rutten, H. J. T. (2018). Optimal management of localized rectal cancer in older patients. Journal of Geriatric Oncology, 9(6), 696-704.

https://doi.org/10.1016/j.jgo.2018.08.001

Document status and date:

Published: 01/11/2018

DOI:

10.1016/j.jgo.2018.08.001

Document Version:

Publisher's PDF, also known as Version of record

Document license:

Taverne

Please check the document version of this publication:

- A submitted manuscript is the version of the article upon submission and before peer-review. There can be important differences between the submitted version and the official published version of record.

People interested in the research are advised to contact the author for the final version of the publication, or visit the DOI to the publisher's website.

- The final author version and the galley proof are versions of the publication after peer review.

- The final published version features the final layout of the paper including the volume, issue and page numbers.

Link to publication

\footnotetext{
General rights rights.

- You may freely distribute the URL identifying the publication in the public portal. please follow below link for the End User Agreement:

www.umlib.nl/taverne-license

Take down policy

If you believe that this document breaches copyright please contact us at:

repository@maastrichtuniversity.nl

providing details and we will investigate your claim.
}

Copyright and moral rights for the publications made accessible in the public portal are retained by the authors and/or other copyright owners and it is a condition of accessing publications that users recognise and abide by the legal requirements associated with these

- Users may download and print one copy of any publication from the public portal for the purpose of private study or research.

- You may not further distribute the material or use it for any profit-making activity or commercial gain

If the publication is distributed under the terms of Article $25 \mathrm{fa}$ of the Dutch Copyright Act, indicated by the "Taverne" license above, 


\title{
Optimal management of localized rectal cancer in older patients
}

\author{
Krzysztof Bujko ${ }^{\text {a }}$, Rob Glynne-Jones ${ }^{\text {b,* }}$, Demetris Papamichael ${ }^{c}$, Harm J.T. Rutten ${ }^{\text {d }}$ \\ a Department of Radiotherapy, Maria Skłodowska-Curie Memorial Cancer Centre, Warsaw, Poland \\ ${ }^{b}$ Mount Vernon Centre for Cancer Treatment, Mount Vernon Hospital, Northwood HA6 2RN, United Kingdom \\ c Department of Medical Oncology, Bank of Cyprus Oncology Centre, Cyprus \\ d Catharina Hospital Cancer Center Eindhoven, GROW Scholl of oncology and developmental Biology, University of Maastricht, the Netherlands
}

\section{A R T I C L E I N F O}

\section{Article history:}

Received 28 May 2018

Received in revised form 19 July 2018

Accepted 1 August 2018

Available online 24 August 2018

\section{Keywords:}

Rectal cancer

Chemoradiation

Radiotherapy

Brachytherapy

Non-operative management

Older adults

\begin{abstract}
A B S T R A C T
In advising the optimal management for older patients, health care professionals try to balance the risks from frailty, vulnerability, and comorbidity against the patient's ultimate prognosis, potential functional outcomes and quality of life (QOL). At the same time it is important to involve the patient and incorporate their preferences. But how can we present and balance the potential downside of radical radiotherapy and risks of unsalvageable recurrence against the potential risks of postoperative morbidity and mortality associated with radical surgery? There are currently no nationally approved and evidence-based guidelines available to ensure consistency in discussions with older adults or frail and vulnerable patients. In this overview we hope to provide an insightful discussion of the relevant issues and options currently available.
\end{abstract}

(C) 2018 Elsevier Ltd. All rights reserved.

\section{Introduction}

In rectal adenocarcinoma, surgery, radiotherapy, and chemoradiotherapy have improved in quality and in selection over the past decade. Survival has increased and local recurrence rates have fallen [1], hence long-term outcomes regarding function, late effects, and quality of life have become more relevant endpoints to evaluate new treatments. As a result, the absolute indications for pre-operative radiotherapy is being continuously re-examined.

Trials have led to the widespread acceptance that the standard of care treatment for patients with locally advanced rectal cancer (T3-T4 or $\mathrm{N}+$ ) is based on short-course radiotherapy (SCRT) using $5 \times 5$ Gray (Gy) or chemoradiotherapy (CRT) using 45-50.4 Gy [2, 3] followed by total mesorectal excision (TME), in other words, a very uniform "one size fits all" standard. In contrast to surgery, these schedules are generally associated with very low rates of mortality in younger patients, although higher rates might be expected in older adults.

In randomised trials, short course preoperative radiotherapy (SCPRT) prior to surgery reduced the 5-year local recurrence (LR) rate [4-8] compared to surgery alone or surgery and selective postoperative radiotherapy or chemoradiotherapy (CRT). Over a similar period preoperative CRT has been shown to reduce local recurrence, to achieve major shrinkage and sometimes completely eradicate tumour, - i.e. a

\footnotetext{
* Corresponding author at: Rob Glynne-Jones ount Vernon Centre for Cancer Treatment, Rickmansworth Road, Northwood, MIDDLESEX HA6 2RN, United Kingdom.

E-mail address: rob.glynnejones@nhs.net (R. Glynne-Jones).
}

pathological complete response ( $\mathrm{pCR}$ ), but has no impact on overall survival when compared to preoperative radiotherapy without chemotherapy or to postoperative chemoradiotherapy [9-12]. When SCPRT and CRT have been directly compared in prospective studies in unselected clinically determined T3/T4 or node-positive rectal patients with cancer, no differences in oncological outcomes were reported $[13,14]$.

Morbidity and mortality have been reported after both CRT or SCPRT. In the NSABP R-03 trial, acute toxic deaths were reported in 5\% of preoperative patients and $3 \%$ of postoperative patients [12]. In the Dutch CARTS study [chemoradiation therapy for rectal cancer in the distal rectum followed by organ-sparing transanal endoscopic microsurgery (TEMS)], CRT-related complications of at least grade 3 occurred in 23 of 55 patients, and 2 out of 55 toxic deaths were reported [15]. In contrast in the Polish trial [16] 2 out of 138 (1.5\%) died during or after the preoperative chemoradiation and prior to surgery and none of the patients during or after $5 \times 5 \mathrm{~Gy}$. Similarly in the TROG 0104 trial there was no 30-day operative mortality [14].

Surgical treatment for older patients is far from being standardized. Historically, options for Hartmann's procedure and local excision were more often selected cases with older patients. In the past, even in fit patients under the age of 70 years, the mortality rate after TME has been reported to be at least $2-5 \%$ and even higher in older adults, 18 ]. However, recent population data suggest that an aggressive policy for assessing and rehabilitating older patients and selection for surgery may be effective in reducing these rates to those associated with younger adults [19]. 
There are alternative options in terms of watch-and-wait, i.e. observation instead of surgery in the event of clinical complete response after preoperative radiotherapy [20]. A watch-and-wait strategy is attractive to surgeons and oncologists and also those who finance healthcare. This strategy may be more suitable for small early and radio-responsive tumours. In addition full-thickness local excision is an additional option (upfront only for T1 polypoid cancers) but preceded by preoperative radiotherapy for cT2-3, <3-4 cm tumours [21-23].

In contrast, to plan a non-operative approach from the outset, there are additional multiple options in terms of the number of fractions, the total radiation dose, the volumes treated [GTV alone or conventional pelvic fields] and whether additional brachytherapy, contact X-ray radiotherapy, neoadjuvant or adjuvant chemotherapy is required. In general, not performing radical surgery after CRT or SCRT represents an opportunistic decision when a complete clinical response (CCR) is observed. Dosimetric studies show that IMRT can achieve improved bowel sparing compared to conventional RT techniques. IMRT is associated with a clinically significant reduction in acute lower GI toxicity compared conformal treatments.

In the previously mentioned randomised radiotherapy trials there is a median age of 68 years and many had an upper age limit of 75 years as eligibility. In practice $40 \%$ of rectal cancers occur in patients aged 75 years or older, who would be expected to have worse compliance, increased acute toxicity, and higher surgical morbidity than younger patients .

There have been recent changes based on recognition of the need to consider older patients in their own right and the development of guidelines from the International Society of Geriatric Oncology (SIOG) [24]. Recent expertise in terms of intensive care and proactive post surgical implementation of enhanced recovery has reduced postoperative mortality and morbidity and made surgery safer. At the same time growing expertise in nonoperative strategeies and the use of higher doses of external beam irradiation, contact X-ray brachytherapy, and high dose rate (HDR) endorectal brachytherapy derive from the increasing interest and experience in the "watch and wait 'initiative.

Hence, in older patients we now try to balance the risks from frailty, vulnerability, and comorbidity $[25,26]$ against the patient's ultimate prognosis, potential functional outcomes, and quality of life (QOL). But how can we present and balance the potential downside of radical radiotherapy and the risks of unsalvageable recurrence against the potential risks of postoperative morbidity and mortality associated with radical surgery? There are currently no nationally approved and evidence-based guidelines available to ensure some consistency in discussions with standard patients -let alone older adults.

Older patients are less represented in clinical trials evaluating chemotherapy and radiotherapy, and it's likely that patients included in these trials are selected because of their fitness and not representative of the routinely seen older patients.

Standard recognised acute toxicities to chemotherapy and radiotherapy probably occur at similar rates in fit older patients to younger ones, but older patients often have less capacity to deal with such toxicities. Thus, oral mucositis/stomatitis or diarrhoea can more rapidly lead to dehydration and acute kidney injury in older adults. A comprehensive geriatric assessment (CGA) may well assess and define a level of frailty, which is common in older adults and in part predicts toxicity. Yet tolerance of treatment requires an individualized assessment of items highlighted by the CGA because of different degrees of fragility, co-morbidity, and a plethora of medications. Hence, treatment then needs to be tailored to each patient -taking into account patient choice, what options you have available in your centre and what you think the patient will tolerate.

A radiotherapy paradox reflects the above issue (Fig. 1). Recently, indications for preoperative radiotherapy have been restricted for small tumours because it does not improve overall survival and is associated with long-term side effects, including impairment of anorectal and sexual functions [15]. On the other hand, it might be beneficial to increase
Radiotherapy paradox in small tumours

Indications for preoperative radiotherapy (RT)

decreased for small tumours increased for small tumours

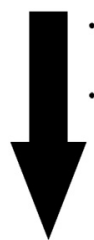

- favourable local control
with TME alone $\begin{aligned} & \text { - watch-and-wait policy possible } \\ & \text { in high rate of patients } \\ & \text { RT causes worsening of } \\ & \begin{array}{l}\text { anorectal functions in } \\ \text { patients undegoing } \\ \text { anterior resection }\end{array} \\ & \begin{array}{l}\text { - better anorectal functions } \\ \text { compared to radical surgery } \\ \text { - No postoperative mortality and } \\ \text { morbidity }\end{array}\end{aligned}$

Fig. 1. This figure depicts radiotherapy paradox in small rectal cancers. Currently, in patients with small tumour, indications for preoperative radiotherapy are reduced because results with total mesorectal excision alone are satisfactory. Moreover, preoperative radiotherapy in such patients increases anorectal dysfunctions and does not improve overall survival. On the another hand, some investigators claim that indications should increase for small tumours because clinical complete response after radiotherapy is more likely than in large cancers. Thus, watch-and-wait policy might often be used and in consequence, patients can avoid postoperative mortality, morbidity and permanent stoma as well have better anorectal functions.

indications for preoperative radiotherapy (even using dose escalation) for these small tumours because a high rate of clinical complete response can then achieved. A watch-and-wait strategy after CRT suggests better anorectal function than after CRT and TME although a third of patients even without major surgery experience majors low anterior resection syndrome (LARS) [27].

Compliance with standard SCPRT and CRT regimens is high [28] and toxicity is acceptable although timing of sugery after SCPRT impacts on mortality $[29,30]$. Hence a gap of six to eight weeks after SCPRT is a rational strategy to reduce surgical morbidity and mortality [31], however rates of pCR after standard SCPRT and delay or CRT are only $11 \%-20 \%$.

Surgical morbidity, which ranges from 6 to 35\%, includes risks of anastomotic leak, pelvic sepsis, pain, and blood loss. Knowledge of such adverse possibilities can deter patients -particularly older patients from accepting radical surgery.

Increases in the aging population and a rising incidence of rectal cancer mean higher numbers of older patients require treatment for rectal cancer. This observation has led to the need for effective methods to assess life expectancy, comorbidities, and health status and an attitude that positive outcomes are possible for older patients.

Traditionally, older patients have probably been undertreated in this setting because of concerns by health care professionals for their comorbidity, frailty, poor functional reserve, and lower performance status. Although 'agist' policies have been common in the past, there is now greater expertise in assessing health status and comorbidity, and even frailty. Many units screen older patients and selectively provide routine geriatric assessment with an emphasis on prehabiliation and an attitude that such patints can achieve levels of fitness which makes radical surgery, radiotherapy, and chemotherapy safer.

However, to our knowledge, no randomised trial of curative rectal cancer surgery has been performed in older patients. Retrospective population studies suggest that older patients do tend to receive a more tailored treatment approach than younger patients if a radical strategy is planned, although many vulnerable and frail older patients are just not referred to surgeons or are excluded from more radical surgical options [32]. Tailored treatment results in similar postoperative complication rates and QOL, but these complications may have a significantly greater negative impact on subsequent physical- and role functioning in older patients [33]. Recovery of functioning is either much slower or permanently affected in older patients. Hence, we still need better methods of predicting postoperative complications in older adults.

Thus, the dilemma is whether to plan a standard of care for older patients or attempt a more tailored customised approach taking into account age, comorbidity, frailty, vulnerability and performance status, or thirdly whether to simply forego the radiotherapy completely [33]. 
In the case of very frail patients sometimes we elect to forego radical surgery and accept that radiotherapy alone will achieve control in some but not all patients [34-36]. In which case, should we use standard of care radiotherapy doses that are shown to be tolerable in younger patients or select a more bespoke treatment with higher doses, where evidence for acceptability and toxicity is sparse and may be unavailable for this older age group? A table of Radiotherapy options in older patients according to levels of fitness or frailty is presented (Table 1).

\section{Case report}

An 84 year old Italian male ex furniture maker presented in November 2014 with rectal bleeding, a mucinous discharge, and frequency of defecation. In the past he had experienced a myocardial infarction. Currently, he has pacemaker and gets short of breath with exercise, but still works in his allotment and enjoys growing vegetables with his wife and makes his own wine. He is a fiercely independent man.

Virtual Colonoscopy showed a cancer in the low/mid rectum but no evidence of liver or lung metastases. MRI precluded because of pacemaker. Flexi-sigmoidoscopy revealed a $3 \mathrm{~cm}$ mass in the left lateral wall of the rectum approximately $7 \mathrm{~cm}$ from the anal verge. The histology showed moderately differentiated adenocarcinoma. In summary G2 cT2NOMx rectal cancer.

He was assessed for surgery, but the anaesthetic assessment was unfavourable - ASA 3/4. On G8 [37] (see appendix), he scored 13/17 (Fig. 2).

He received standard short course pelvic radiotherapy $(5 \times 5 \mathrm{~Gy})$ between $29 / 12 / 14$ and $05 / 01 / 2015$. When seen $11 / 2 / 2015$, the patient was well, with no further bleeding, but some clustering two to three times in the morning. Clinically on digital rectal examination (DRE) he had achieved a complete clinical response, confirmed by CT (Fig. 3).

The MDT decided there was no need for a brachytherapy boost. The patient was seen regularly at 3 monthly intervals until 19 August 2015, when he described further bleeding, but was still working in his allotment. Repeat CT showed thickening in the area of the primary tumour in mid and upper rectum. In view of further rectal bleeding he received a 10 Gy single fraction of brachytherapy in September 2015.

Further bleeding occurred six months later in April 2016, but CT showed no change. He refused the offer of a colostomy, and underwent fulguration of a small exophytic recurrence. The patient continued to experience further intermittent rectal bleeding, but he maintained his haemoglobin 12.5-12.9 g. He was last seen in August 2nd 2017. He described working in his allotment, and denied any pain. At that time CT showed residual thickening in area of primary tumour in mid and upper rectum but no metastases. We were notified that the patient had died suddenly at home aged 87 in September 2017.

\section{Discussion}

\subsection{Surgery}

Despite the fact that new non-surgical techniques are emerging for the treatment of early rectal cancer, surgery alone still offers the best chance for cure for the majority of patients. Nevertheless, there are some serious draw backs to surgery, which include the mortality associated with surgery persisting up a year after the resection.

In 2008, it was demonstrated that in 75-84 and 85-95 year old patients in the Dutch TME study the 30-day postoperative mortality was higher than in younger patients: $6.5 \%$ and $11.8 \%$ versus $1.4 \%$ and $3.2 \%$ for younger than 65 years and 65 to 74 year old patients, respectively. These findings were validated against population-based data on rectal cancer [38]. Even more confusing was that the increased risk of dying after rectal resection persisted in the elderly for almost six months, and effectively doubled the 30-day mortality rate to $13.4 \%$ and $17.6 \%$ for 75-84 year old and 85-95 year old patients respectively. This was confirmed in both rectal and colon cancer surgery [39]. The Association
Table 1

Radiotherapy options in older patients according to levels of fitness or frailty.

Fit patients

- Consider indications for preoperative radio(chemo)therapy the same as for fit younger patients.

- To balance risk-benefit ratio, consider limitation of clinical target volume (CTV). For example, external iliac nodes may not be included into CTV for cT4 or extensive nodal disease because the risk of recurrence in this area is very low [78]. Similarly, for low or mid rectal cancers lowering the upper CTV border to S2/S3 interspace does not put most patients at increased risk for recurrence $[79,80]$.

- The least toxic approach is delivering $5 \times 5 \mathrm{~Gy}$ with $4-8$ week interval to surgery [34]. This schedule can be utilised not only in intermitted risk cancers but also when mesorectal fascia is threatened [81]

- In the event of decision to apply combination of radio- and chemotherapy consider using $5 \times 5 \mathrm{~Gy}$ and short 5 -fu/leucovorin chemotherapy after 10-day interval [82, 83]. This management assures lower acute toxicity and similar local efficacy to that observed after conventionally fractionated simultaneous chemoradiation.

- Consider watch-and-wait policy in patients with clinical complete response also in those receiving $5 \times 5$ Gy $[23,57,53]$

Medium fit patients at

surgical risk

- All the above remarks aimed at reducing toxicity are valid also for this group of patients.

- Limitation of CTV may go even further, especially for patients without nodal disease and with small primary tumour. Obturator nodes might be excluded from CTV. Margin of uninvolved mesorectal or presecral tissue from the gross disease might be reduced to $3-5 \mathrm{~cm}$ in the cranial direction and to $2-4 \mathrm{~cm}$ in the caudal direction in case of high or mid cancer. Both intramural and mesorectal cancer spread beyond those limits occur rarely.

- For patients with cT2 or cT3a/cT3b (the depth of mesorectal fat infiltration shorter than $1 \mathrm{~mm} / 5$ $\mathrm{mm}$ ) disease consider up-front radiotherapy with organ preservation intent, i.e. watch-and-wait procedure for those with clinical complete response or full-thickness local excision for those with near clinical complete response/small residual tumour [Morrino 2015, 25, 26, 84]. Alternatively, in the latter case, consider radiotherapy boost using contact X-ray or endoluminal high dose rate brachytherapy instead of local excision [35, 39, 85].

- For patients after local excision of high risk cancer (deep submucosal infiltration, lymphovascular invasion, G3 malignancy or positive margin) consider postoperative radiotherapy instead of conversion to radical surgery [86].

Frail patients, radical surgery contraindicated

For early and medium size tumours consider radical radiotherapy using external beam irradiation combined with contact X-ray or endoluminal high dose rate brachytherapy [35, 36, 44, 85].

- For tumours deeply infiltrating and/or involving anal canal consider external beam conventionally fractionated radiotherapy even up to $66 \mathrm{~Gy}$ if a tumour is located extraperitoneally $[37,88]$.

Palliative setting

- For very frail patients consider $5 \times 5 \mathrm{~Gy}$ to CTV that included only gross tumour with small margin. Such treatment may assure long-lasting tumour control and makes possible avoidance of diverting stoma in a majority of patients [87].

of Coloproctology of Great Britain and Ireland illustrated that postoperative mortality rHow about ate after curative surgery in stage 2 and stage 3 rectal cancer was associated with ASA score [40].

Postoperative mortality in most older patients is currently no different from their younger counterparts, and the excess mortality previously reported in the first year after surgery has also subsided even in 


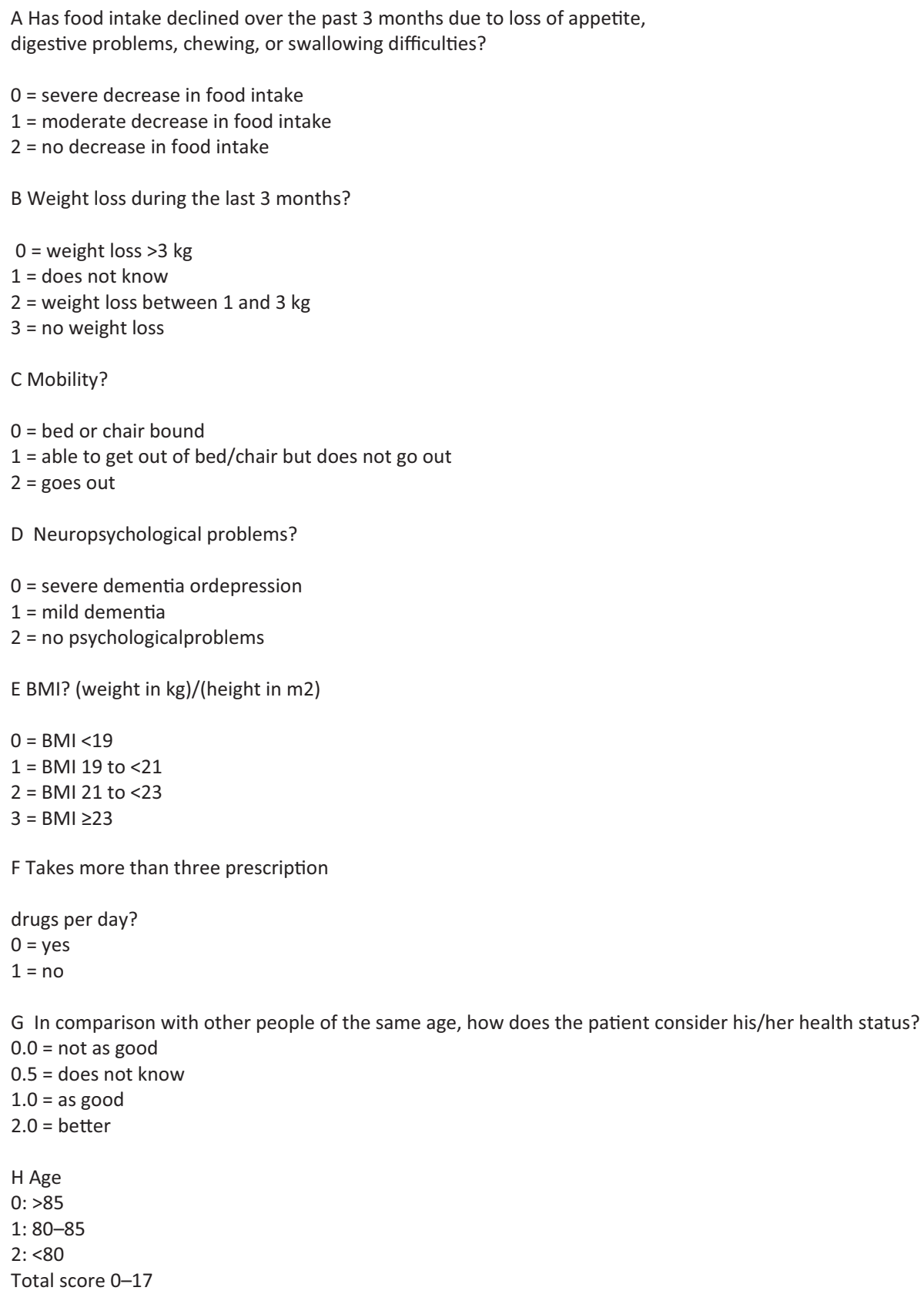

Fig. 2. The G-8 questionnaire Items Possible responses (score).

patients with comorbidity and considered less fit, as shown in a recent nationwide population study in the Netherlands [41]. (Fig. 4.)

These data are from historical studies, almost two decades ago. Since then surgical management of older patients with rectal cancer has

cT2NO $3 \mathrm{~cm}$ tumour- what to do now?

1. Radical Surgery?

2. Local excision?

3. RT and then local excision?

4. RT and then radical surgery?

5. RT alone?

Fig. 3. What is the most appropriate management for this patient? changed drastically. Instead of general surgeons, these patients are now operated upon by specialised colorectal surgeons. Anesthesiological techniques have improved avoiding hypothermia, electrolyte disturbances, as well as hyper and hypovolemia. Postoperative nutritional and physical activity interventions have become standard in most hospitals. Postoperative mortality in most older patients is currently no different from their younger counterparts, and the excess mortality previously reported in the first year after surgery has also subsided even in patients with comorbidity and considered less fit, as shown in a recent nationwide population study in the Netherlands (Focus on elderly 2016) [41].

In depth analysis of these population data show that modern rectal surgery has become much safer and that conclusions from older datasets have to be revoked. In the age group of 75-85 years of age the percentage of resected patients declines over the years comparable to other younger age groups. It is likely that this improvement reflects better staging, which then avoids the need for resection in patients 


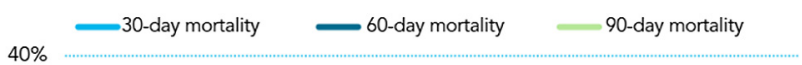

$30 \%$

$20 \%$

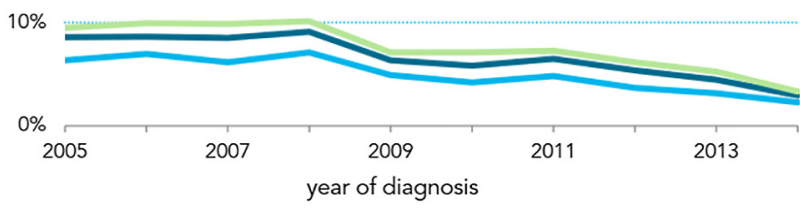

trends in postoperative 30,60 and 90-day mortality in patients $\geq 70$ years with stage I-IV rectum carcinoma, per year of diagnosis $(n=12,471)$

Fig. 4. Postoperative mortality is becoming low and is no longer different from younger patients. Furthermore, excess mortality after 30 day mortality has disappeared. (Ref. [44]).

with distant metastases, and also other non-surgical treatments are increasingly available (data not shown).

Demographic population structure will show a rapid increase of the age group of 75-85 years, which happens to be the group with the highest incidence of rectal cancer. Life expectancy gradually decreases from 12.5 years for the 75 year old to 6.5 years for the 85 year old (data Central Bureau of Statics, The Netherlands 2017). Meaning, that a less effective management than surgery potentially will confront the patient with progressive tumour growth before the patient has the chance to die from other causes, and it is likely the patient will die from the complications of progressive growth and will require more intense treatment in the end, even at a higher age. Only the very frail have a smaller chance of outliving progression of ineffectively treated rectal cancer.

Progressive tumour growth can lead to emergency situations, which inherently are associated with more postoperative complications and higher mortality.

A colorectal surgeon working with the elderly should be acquainted with geriatric conditions which may lead to higher vulnerability of the patient, and which should trigger perioperative interventions or even deferral from surgery. The Dutch Cancer Registry demonstrates that three-quarter of patients aged 75 and older with rectal cancer will undergo a resection in stage I - III rectal cancer without higher early or late postoperative mortality.

Particularly in the case of early rectal cancer an elective resection is effective and safe even in the elderly, and hence should always be part of shared discussion making.

\subsection{Radiotherapy}

There seems a dose-response relationship for tumour regression after preoperative CRT for rectal cancer for smaller earlier T1-T2 stage cancers if not for larger more advanced cT3 tumours. Variation in tumour stage, chemotherapy and radiotherapy techniques may confound the analysis, but response to radiotherapy does appear to depend strongly on tumour size (as measured from the diameter and length on the pre-treatment MRI scan) [42, 43].

External beam radiotherapy (EBRT) doses could be escalated from the outset to increase the chance for tumour control without surgery for patients at high surgical risk. Dose escalation has been explored in early cancers [44] and in elderly or medically inoperable patients [35]. In the former study clinical complete response was achieved in $78 \%$ patients.
In the latter Phase I Herbert study $(n=38)$ external beam radiotherapy $(13 \times 3 \mathrm{~Gy}$ ) was followed by three weekly high dose rate endorectal brachytherapy (HDR-EBRT) a [35], and reported a complete clinical response in $61 \%$ of patients, with a $60 \%$ two-year local progression-free survival.

These response-rates are encouraging, but there is a risk of toxicity. These studies reported late toxicity in terms of rectal bleeding (any grade in 78\% patients and grade 3 in 7\%) [44] and grade 2 and $\geq 3$ proctitis in $48 \%$ and $40 \%$ respectively [45]. The sample size is too small and follow-up too short to recommend such management as routine. Nevertheless, older patients at high surgical risk, especially requiring abdomino-perineal resection, could be candidates for such schedules.

Dose escalation has also been used either with contact X-ray HDR or brachytherapy in small early tumours. A retrospective series $(n=41)$ from France of cT2 and early T3 $\leq 4 \mathrm{~cm}$ cancers treated with contact Xray brachytherapy alone or combined with external beam radiotherapy $(25 \times 2 \mathrm{~Gy})$ or chemoradiotherapy, followed by surveillance or local excision, showed a clinical complte response 96\% [36]. At five -years, local recurrence rate was $11 \%$.

In the USA, evidence from the National Cancer Database suggests an increasing role for avoidance of surgery after CRT [46, 47]. Some of this increase is reported in black, older, and uninsured or Medicaid patients and in small volume centres [47], and may not imply optimal management or selection. Older patients and female patients were more likely than younger patients not to undergo surgery (age by decade AOR, 1.14 [ $95 \% \mathrm{CI}, 1.11$ to 1.18 ]. Hence, it is not clear whether this strategy reflects the informed attitudes of surgeons and radiation oncologists, accepting more inclusive decision-making and patient choice or simply considerations of cost.

There are other important endpoints, which are not documented in this report viz. the number of temporary stomas never reversed. Data from individual series [48] and populations [49] suggest $10 \%-50 \%$ of patients with a temporary stoma are never reversed, and preoperative SCPRT and CRT are independent risk factors [48].

So the evidence needs to be carefully scrutinised. Failure to proceed to radical surgery after chemoradiation (CRT) is not necessarily the same strategy nor has the same outcomes as a carefully selected watch-and-wait policy in the face of complete clinical response [50].

However, there are complex issues, since counterintuitively, a UK study found that for patients with rectal cancer aged 80 years and older, surgery was associated with better survival than non-operative treatment [51].

The International Watch \& Wait Database (IWWD; http://iwwd.org/ news/) is an international project initiated by the Champalimaud Foundation, Portugal and the European Registry of Cancer Care (EURECCA). Data is collected for patients who achieve a CCR at twelve weeks after chemoradiation and who undergo a non-operative strategy. The preliminary results presented in 2017 [52] reported on 775 patients from 35 institutions. Local re-growth occurred in $25 \%$ of patients, but the majority were salvaged by surgery, such that three-year overall survival was $87 \%$ in patients with local regrowth, and $91 \%$ in the total group of patients.

\section{3. $5 \times 5 G y$ or $C R T$}

When SCPRT and CRT have been compared in prospective studies in unselected clinically determined T3/T4 or node-positive patients with rectal cancer, no differences in oncological outcomes were reported $[10,11]$ - so the two strategies appear equally effective in resectable cancers if radical TME is performed. However, another Polish small randomised trial [53] examining local excision, compared 5 X 5Gy versus CRT and found that following CRTand local excision the local recurrence rate was lower in the CRT arm compared to $5 \times 5 \mathrm{~Gy}$ and local excision (5\% versus 35\% at ten-years; $P=.036$ ). Although numbers are quite small in this trial and there may be unsuspected biases. We 
have no data to compare CRT or SCRT if a non-operative strategy is planned.

When $5 \times 5$ Gy was given to 30 patients with a median age of 77 years in a non-operative approach, of whom $18 / 30$ (60\%) were cT2 stage and 6/30 (20\%) achieved a complete clinical response. Only 1/6 of these patients experienced a local regrowth. The authors provided no data on late effects or QOL [54]. A similar UK study of $5 \times 5$ Gy followed by transanal endoscopic microsurgery [55] showed that 7/60 (12\%) recurred and late complications beyond twelve months were reported in only $6 / 60(10 \%)$ patients. However, the details details regarding late effects are so sparse and the follow-up so short in this small number of patients that no robust conclusions can be drawn from this data.

Shorter overall treatment may be better or more appropriate in the older patient. Fewer fractions may offer better compliance and less acute toxicity. Also, fewer visits may overcome financial and social barriers to treatment, such as travel distance from home to hospital.

In summary, the use of the Vaizey incontinence score showed continence after 'watch-and-wait' can be good following CRT [56], although more recent data implies that at least one third of patients will experience severe LARS syndrome [27]. It remains unclear whether these late effects reflect an advanced local tumour, or the result of CRT treatment. However, currently we have no data to use to counsel a patient as to their expected fuction and QOL after $5 \times 5 \mathrm{~Gy}$ in a non-operative approach.

\subsection{Adjuvant chemotherapy for fully resected rectal cancer following neo- adjuvant therapy or definitive therapy}

Early trials $[57,58]$ and a pooled analysis [59] from the pre-TME era demonstrated a $25-30 \%$ relative risk reduction in mortality and distant metastasis with the use of adjuvant chemotherapy compared to surgery alone. A more recent Cochrane Review from 2012 which included $>9000$ patients from 21 trials also suggested a small but statistically significant gain from the use of adjuvant chemotherapy (Hazard Ratio (HR) for overall survival (OS) 0.88 (0.76-0.91) DFS 0.75 (0.68-0.83)) [60]. Trials included in this review run through multiple decades and had great heterogeneity. Nevertheless, since the publication of these trials, the treatment of rectal cancer has evolved.

A number of relatively recent trials have examined the role of adjuvant chemotherapy for locally advanced rectal cancer. In the EORTC 22921 patients with T3-4 rectal cancer were randomly assigned to pre-operative RT, preoperative chemoradiation, preoperative RT and postoperative chemotherapy or preoperative chemoradiation and postoperative chemotherapy [8]. Despite long-term follow-up, there was no effect on OS or DFS for the addition of adjuvant chemotherapy in any of the study arms [61]. The study was criticised for being underpowered and for using a lower than 'standard' bolus 5-Fluorouracil (5FU)regimen. Another randomised trial [62] included 655 patients with cT3-4 disease who underwent neoadjuvant chemoradiation and surgery. Patients received either 6 cycles of bolus FU or simple followup. At five- years there was no difference in OS, local recurrence or distant spread.

The PROCTOR-SCRIPT trial [63] randomly assigned patients with histologically proven stage II/III rectal cancer who received neoadjuvant RT or chemoradiation and TME to adjuvant chemotherapy vs observation. With 437 patients randomised, the study closed due to poor accrual. After a median follow-up of five-years it showed no difference for OS, DFS, local recurrence or metastases. Chronicle, a UK study, closed prematurely after accruing 113 patients from a target of 800. Patients were randomly assigned to six cycles of adjuvant oxaliplatin plus capecitabine vs observation following neoadjuvant radiation and resection. No differences were observed in OS and DFS, while $<50 \%$ of the patients assigned to chemotherapy completed a total of six cycles [64]. A subsequent meta-analysis of individual data from four randomised trials included 1196 patients stage II/III rectal cancer who received neoadjuvant therapy and surgical resection [65]. No differences were seen in OS, DFS or distant spread.

Even though multiple studies have evaluated the optimal regimen in adjuvant chemotherapy for colon cancer, this has not been the case for rectal cancer. The 'ADORE trial', a multicentre randomised phase II trial examined the use of FOLFOX vs a 5FU/LV regimen in the setting of 321 patients who received prior chemoradiation and surgery with a pathologic stage II/III disease [66]. With a median follow-up of just over 3 years there was a statistically significant improvement in DFS in favour of FOLFOX (71.6\% vs 62.9\%, HR 0.657, $p=.047$ ).

The optimal duration of adjuvant chemotherapy in rectal cancer has not been addressed in any clinical trials. It is quite likely however, that future clinical trail design may be influenced by the recent IDEA collaboration $[67,70]$. This large trial suggested that at least for non-high risk patients (T3 N1) three months of chemotherapy with CAPEOX may be enough. As the landscape of treatment for rectal cancer continues to evolve, the question of adjuvant chemotherapy may become increasingly difficult to answer.

Newer Phase III trials considering the question of total neoadjuvant therapy (RAPIDO) $[68,71]$ or the question of doing without radiotherapy altogether (CALGB PROSPECT/Allianz N1048 trial) (NCT01515787) will be reported over the next few years.

Turning now to older patients with rectal cancer and considerations for adjuvant chemotherapy, treatment decisions can be very challenging. Older patients with colon cancer do not appear to derive the same benefit from the addition of oxaliplatin (FOLFOX, CAPEOX) although they stand to benefit from treatment with a fluoropyrimidine [69]. Does it therefore follow that oxaliplatin-containing chemotherapy should not be offered to patients over 70 with rectal cancer in the adjuvant setting? So far, whenever data have been lacking in rectal cancer adjuvant therapy, predicted results were extrapolated from colon cancer trial findings with hardly any evidence basis. The potential downfalls of this approach can be easily appreciated. Patients with rectal cancer can have different patterns of recurrence and different disease biology from those with colon cancer (Missiaglia E, et al. Ann Oncol 2014;25:1995-2001, Lee GH, et al. Eur J Surg Oncol 2015;41:300-8, Guinney J, et al. Nat Med 2015;21:1350-6). In addition, older patients can have varying surgical morbidity as well as different tolerance to adjuvant therapy. Indeed, for patients over the age of 75 there is hardly any evidence basis for adjuvant therapy since very few of those patients were included in randomised adjuvant trials. Unfortunately, internationally accepted guidelines $[15,24]$ do not provide answers either.

\subsection{Patient choice}

We acknowledge that "individualisation of care for rectal cancer patients is essential". However, the older patient is not always so closely part of the decisions-making. Some patterns of care are simply unwanted. Patients have different views as to what is a worthwhile benefit from preoperative radiotherapy in rectal cancer and many would feel this is not worthwhile $[73,74]$. If the outcome of treatment was cure but would lead to loss of functional independence or cognitive impairment, $74 \%$ of patients would not choose treatment $[72,75]$.

Clinicians are embracing shared decision-making, which requires sufficient information for patients in order to exercise choice. Effective collaboration of team members to facilitate communication of options to patients in situations where difficult decisions have to be reached. We recommend first that a caregiver is present at discussions if at all possible. It is also helpful to ask a patient to nominate a person that provides support for them and include their contact details if not the same as the patient or caregiver- so they can also be briefed. The clinical nurse specialist (CNS) or nurse navigator often has a crucial role in determining the patient's preferences. Older patients can struggle as more and more information is provided some of which is complex. The expertise, empathy and time available from the CNS (in contrast to surgeons and oncologists) can facilitate shared and informed decision-making rather 
than informed consent. Some surgeons use Best Case/Worst Case scenarios [76]. There are also a number of decision aids which are beyond the scope of this article to discuss [77].

\section{Conclusion}

Radiotherapy has been a key component of the management of older patients with rectal cancer because of concerns regarding morbidity of major surgery. To some extent this anxiety is unfounded because in the modern era suitable patients can be selected for surgery with the use of a CGA and prehabilitation. However data regarding the CGA and toxicity in this subset of patients are still scarce and controversial. Recent technological improvements in the delivery of radiation may significantly contribute to the management of the older population and can improve compliance. However, little is known of the benefit of modified chemotherapy or radiotherapy schedules in older patients or their preferences in terms of choosing between surgery and radiation. We have many prognostic factors but few predictive factors as to who will respond or not and who will benefit or not from radiation. We know little regarding the late functional outcomes from $5 \times 5$ Gy alone in a watch and wait strategy, nor their ultimate QOL. Although there are guidelines for fit older adults, we still need guidelines on treatment options for older frail and vulnerable patients. Hence, we need more research and better understanding and guidance in using chemotherapy and radiotherapy and surgery in older patients. The essence is therefore to match any or all of the three potential treatment modalities as a single or combined approach according to the wishes and expectations of the patient. Even then, no perfect guideline will be possible for all patients, hence management of older patients requires a sensitive and empathic multidisciplinary individualized approach with highly qualified and experienced members.

\section{Conflicts of interest}

Rob Glynne-Jones, Krysztoff Bujko, Demetris Papamichael and Harm Rutten have no conflicts of interest to declare.

\section{Authors contributions}

All authors (RGJ,KB,DP,HR) participated in the manuscript conception and development, provision of data and references. RGJ drafted the manuscript with sections contributed by other three authors. All authors made critical revisions. All authors approved the final manuscript.

\section{References}

[1] Glimelius B, Myklebust TÅ, Lundqvist K, Wibe A, Guren MG. Two countries - two treatment strategies for rectal cancer. Radiother Oncol 2016 Dec;121(3):357-63.

[2] Glynne-Jones R, Wyrwicz L, Tiret E, Brown G, Rödel C, Cervantes A, et al. ESMO Guidelines Committee. Rectal cancer: ESMO Clinical Practice Guidelines for diagnosis, treatment and follow-up. Ann Oncol 2017 Jul 1;28(suppl_4):iv22-40.

[3] National Clinical Practice Guidelines in Oncology (NCCN Guidelines). Rectal Cancer Version Version 2.2018 - June 27. www.ncrn.org; 2018. (accessed 10/07/2018).

[4] Anon. Improved survival with preoperative radiotherapy in resectable rectal cancer Swedish Rectal Cancer Trial. N Engl J Med 1997;336:980-7.

[5] Kapiteijn E, Marijnen CA, Nagtegaal ID, Putter H, Steup WH, Wiggers T, et al. Preoperative radiotherapy combined with total mesorectal excision for resectable rectal cancer. N Engl J Med 2001 Aug 30;345(9):638-46.

[6] Peeters KC, Marijnen CA, Nagtegaal ID, Kranenbarg EK, Putter H, Wiggers T, et al. The TME trial after a median follow-up of 6 years: increased local control but no survival benefit in irradiated patients with resectable rectal carcinoma. Ann Surg 2007; 246(5):693-701.

[7] Sebag-Montefiore D, Stephens RJ, Steele R, Monson J, Grieve R, Khanna S, et al. Preoperative radiotherapy versus selective postoperative chemoradiotherapy in patients with rectal cancer (MRC CR07 and NCIC-CTG C016): a multicentre, randomised trial. Lancet 2009 Mar 7;373(9666):811-20.

[8] Quirke P, Steele R, Monson J, Grieve R, Khanna S, Couture J, et al. MRC CR07/NCICCTG CO16 trial investigators; NCRI colorectal Cancer study group. Effect of the plane of surgery achieved on local recurrence in patients with operable rectal cancer: a prospective study using data from the MRC CR07 and NCIC-CTG CO16 randomised clinical trial. Lancet 2009;373(9666):821-8.
[9] Sauer R, Becker H, Hohenberger W, Rödel C, Wittekind C, Fietkau R, et al. German rectal Cancer study Group.Preoperative versus postoperative chemoradiotherapy for rectal cancer. N Engl J Med 2004;351(17):1731-40.

[10] Gérard JP, Conroy T, Bonnetain F, Bouché O, Chapet O, Closon-Dejardin MT, et al. Preoperative radiotherapy with or without concurrent fluorouracil and leucovorin in T3-4 rectal cancers: results of FFCD 9203. J Clin Oncol 2006;24(28):4620-5.

[11] Bosset JF, Collette L, Calais G, Mineur L, Maingon P, Radosevic-Jelic L, et al. EORTC radiotherapy group trial 22921. Chemotherapy with preoperative radiotherapy in rectal cancer. N Engl J Med 2006;355(11):1114-23.

[12] Roh MS, Colangelo LH, O'Connell MJ, Yothers G, Deutsch M, Allegra CJ, et al. Preoperative multimodality therapy improves disease-free survival in patients with carcinoma of the rectum: NSABP R-03. J Clin Oncol 2009;27(31):5124-30.

[13] Bujko K, Nowacki MP, Nasierowska-Guttmejer A, Michalski W, Bebenek M, Kryj M. Long-term results of a randomised trial comparing preoperative short-course radiotherapy with preoperative conventionally fractionated chemoradiation for rectal cancer. Br J Surg 2006;93:1215-23.

[14] Ngan SY, Burmeister B, Fisher RJ, Solomon M, Goldstein D, Joseph D, et al. Randomized Trial of short-course radiotherapy versus long-course chemoradiation comparing rates of local recurrence in patients with $\mathrm{T} 3$ rectal cancer: trans-tasman radiation oncology group trial 01.04. J Clin Oncol 2013 Jan 20;31(3):399.

[15] Verseveld M, de Graaf EJ, Verhoef C, van Meerten E, Punt CJ, de Hingh IH, et al, CARTS Study Group. Chemoradiation therapy for rectal cancer in the distal rectum followed by organ-sparing transanal endoscopic microsurgery (CARTS study). Br J Surg 2015 Jun;102(7):853-60.

[16] Wawok P, Polkowski W, Richter P, Szczepkowski M, Olędzki J, Wierzbicki R, et al. Preoperative radiotherapy and local excision of rectal cancer: long-term results of a randomised study. Radiother Oncol 2018;127:396-403.

[18] Glynne-Jones R, Wyrwicz L, Tiret E, Brown G, Rödel C, Cervantes A, et al. ESMO Guidelines Committee. Rectal cancer: ESMO Clinical Practice Guidelines for diagnosis, treatment and follow-up. Ann Oncol 2017 Jul 1;28(suppl_4):iv22-40.

[19] National Clinical Practice Guidelines in Oncology (NCCN Guidelines). Rectal Cancer Version Version 2.2018 - June 27. www.ncrn.org; 2018. (accessed 10/07/2018).

[20] Holm T, Rutqvist LE, Johansson H, Cedermark B. Postoperative mortality in recta cancer treated with or without preoperative radiotherapy: causes and risk factors. Br J Surg 1996;83:964-8.

[21] Smith FM, Rao C, Oliva Perez R, Bujko K, Athanasiou T, Habr-Gama A, et al. Avoiding radical surgery improves early survival in elderly patients with rectal cancer, demonstrating complete clinical response after neoadjuvant therapy: results of a decision-analytic model. Dis Colon Rectum 2015 Feb;58(2):159-71.

[22] Focus on Cancer Care - the Elderly Patient. Report of the Dutch Cancer Registry English Version; 2018.

[23] Sammour T, Price BA, Krause KJ, Chang GJ. Nonoperative management or 'Watch and Wait' for rectal Cancer with complete clinical response after neoadjuvant Chemoradiotherapy: a critical appraisal. Ann Surg Oncol 2017;24:1904-15.

[24] Morino M, Risio M, Bach S, Beets-Tan R, Bujko K, Panis Y, et al, European Association for Endoscopic Surgery, European Society of Coloproctology. Early rectal cancer: the European Association for Endoscopic Surgery (EAES) clinical consensus conference. Surg Endosc 2015 Apr;29(4):755-73.

[25] Hallam S, Messenger DE, Thomas MG. A systematic review of local excision after neoadjuvant therapy for rectal Cancer: are ypT0 tumors the limit? Dis Colon Rectum 2016;59:984-97.

[26] Rullier E, Rouanet P, Tuech JJ, Valverde A, Lelong B, Rivoire M, et al. Organ preservation for rectal cancer (GRECCAR 2): a prospective, randomised, open-label, multicentre, phase 3 trial. Lancet 2017:390(10093):469-79.

[27] Papamichael D, Audisio RA, Glimelius B, de Gramont A, Glynne-Jones R, Haller D et al. Treatment of colorectal cancer in older patients: International Society of Geriatric Oncology (SIOG) consensus recommendations 2013. Ann Oncol 2015 Mar; 26(3):463-76.

[28] Stornes T, Wibe A, Endreseth BH. Complications and risk prediction in treatment of elderly patients with rectal cancer. Int J Colorectal Dis 2016;31:87-9.

[29] Yeo HL, O'Mahoney PR, Lachs M, Michelassi F, Mao J, Finlayson E, et al. Surgical oncology outcomes in the aging US population. J Surg Res 2015;2016:11-8.

[30] Hupkens BJP, Martens MH, Stoot JH, Berbee M, Melenhorst J, Beets-Tan RG, et al Quality of life in rectal Cancer patients after Chemoradiation: watch-and-wait policy versus standard resection - a matched-controlled study. Dis Colon Rectum 2017;60: $1032-40$.

[31] Guimas V, Boustani J, Schipman B, Lescut N, Puyraveau M, Bosset JF, et al. Preoperative Chemoradiotherapy for rectal Cancer in patients aged 75 years and older: acute toxicity, compliance with treatment, and early results. Drugs Aging 2016 Jun;33(6): 419-25.

[32] Marijnen CA, Kapiteijn E, van de Velde CJ, Martijn H, Steup WH, Wiggers T, et al. Cooperative investigators of the Dutch colorectal Cancer group. Acute side effects and complications after short-term preoperative radiotherapy combined with total mesorectal excision in primary rectal cancer: report of a multicenter randomized trial. J Clin Oncol 2002 Feb 1;20(3):817-25.

[33] Van den Broek CB, van Gijn W, Bastiaannet E, Møller B, Johansson R, Elferink MA et al. EURECCA consortium. Differences in pre-operative treatment for rectal cancer between Norway, Sweden, Denmark, Belgium and the Netherlands. Eur J Surg Oncol 2014;40(12):1789-96.

[34] Erlandsson J, Holm T, Pettersson D, Berglund Å, Cedermark B, Radu C, et al. Optima fractionation of preoperative radiotherapy and timing to surgery for rectal cancer (Stockholm III): a multicentre, randomised, non-blinded, phase 3, non-inferiority trial. Lancet Oncol 2017 Mar;18(3):336-46.

[35] Guillerme F, Clavier JB, Nehme-Schuster H, Leroy V, Heitz D, Schumacher C, et al. Age impacts the pattern of care for elderly patients with rectal cancer. Int J Colorectal Dis 2014;29:157-63. 
[36] Couwenberg AM, de Beer FSA, Intven MPW, Burbach JPM, Smits AB, Consten ECJ, et al. The impact of postoperative complications on health-related quality of life in older patients with rectal cancer; a prospective cohort study. J Geriatr Oncol 2018 9(2):102-9.

[37] Brierley JD, Cummings BJ, Wong CS, Keane TJ, O'Sullivan B, Catton CN, et al. Adenocarcinoma of the rectum treated by radical external radiation therapy. Int J Radiat Oncol Biol Phys 1995;31:255-9.

[38] Rijkmans EC, Cats A, Nout RA, van den Bongard DHJG, Ketelaars M, Buijsen J, et al. Endorectal brachytherapy boost after external beam radiation therapy in elderly or medically inoperable patients with rectal Cancer: primary outcomes of the phase 1 HERBERT study. Int J Radiat Oncol Biol Phys 2017;98: 908-17.

[39] Frin AC, Evesque L, Gal J, Benezery K, François E, Gugenheim J, et al. Organ or sphincter preservation for rectal cancer. The role of contact X-ray brachytherapy in a monocentric series of 112 patients. Eur J Cancer 2017;72:124-36.

[40] Decoster L, Van Puyvelde K, Mohile S, Wedding U, Basso U, Colloca G, et al. Screening tools for multidimensional health problems warranting a geriatric assessment in older cancer patients: an update on SIOG recommendations. Ann Oncol 2015;26: 288-300.

[41] Rutten HJ, den Dulk M, Lemmens VE, van de Velde CJ, Marijnen CA. Controversies of total mesorectal excision for rectal cancer in elderly patients. Lancet Oncol 2008 May:9(5):494-501.

[42] van Gestel YR, Lemmens VE, de Hingh IH, Steevens J, Rutten HJ, Nieuwenhuijzen $\mathrm{GA}$, et al. Influence of comorbidity and age on 1-, 2-, and 3-month postoperative mortality rates in gastrointestinal cancer patients. Ann Surg Oncol 2013 Feb; 20(2):371-80.

[43] Tan E, Tilney H, Thompson M, Smith J. Tekkis PP; Association of Coloproctology of Great Britain and Ireland. The United Kingdom National Bowel Cancer Project epidemiology and surgical risk in the elderly. Eur J Cancer 2007 Oct;43(15): 2285-94.

[44] https://shop.iknl.nl/shop/kankerzorg-in-beeld-de-oudere-patient-(2016)/123187.

[45] Jakobsen A, Ploen J, Vuong T, Appelt A, Lindebjerg J, Rafaelsen SR. Dose-effect relationship in chemoradiotherapy for locally advanced rectal cancer: a randomized trial comparing two radiation doses. Int J Radiat Oncol Biol Phys 2012 Nov 15; 84(4):949-54.

[46] Appelt AL, Pløen J, Vogelius IR, Bentzen SM, Jakobsen A. Radiation dose-response model for locally advanced rectal cancer after pre-operative chemoradiotherapy. Int J Radiat Oncol Biol Phys 2013 Jan 1;85(1):74-80.

[47] Appelt AL, Pløen J, Harling H, Jensen FS, Jensen LH, Jørgensen JC, et al. High-dose chemoradiotherapy and watchful waiting for distal rectal cancer: a prospective observational study. Lancet Oncol 2015 Aug;16(8):919-27.

[48] Rijkmans EC, van Triest B, Nout RA, Kerkhof EM, Buijsen J, Rozema T, et al. Evaluation of clinical and endoscopic toxicity after external beam radiotherapy and endorectal brachytherapy in elderly patients with rectal cancer treated in the HERBERT study. Radiother Oncol 2018 Mar;126(3):417-23 (pii: S0167-8140(17)32778-0).

[49] Abrams MJ, Koffer PP, Leonard KL. The emerging non-operative management of non-metastatic rectal cancer: a population analysis. Anticancer Res 2016 Apr: 36(4):1699-702.

[50] Ellis CT, Samuel CA, Stitzenberg KB. National Trends in nonoperative Management of Rectal Adenocarcinoma. J Clin Oncol 2016 May 10;34(14):1644-51.

[51] Sier MF, van Gelder L, Ubbink DT, Bemelman WA, Oostenbroek RJ. Factors affecting timing of closure and non-reversal of temporary ileostomies. Int J Colorectal Dis 2015 Sep;30(9):1185-92.

[52] NBOCAP. In: Partnership HQI, editor. National Bowel Cancer Audit Report 2016; 2016 London.

[53] Habr-Gama A, Perez RO. No surgery after chemoradiation is not equal to nonoperative management after complete clinical response and chemoradiation. J Clin Oncol 2016 Nov 20;34(33):4051.

[54] Bhangu A, Kiran RP, Audisio R, Tekkis P. Survival outcome of operated and non-operated elderly patients with rectal cancer: a surveillance, epidemiology, and end results analysis. Eur J Surg Oncol 2014 Nov:40(11):1510-6.

[55] van der Valk M. International Watch and Wait Database Consortium. The International Watch \& Wait database (IWWD) for rectal cancer: an update. J Clin Onco 2017;35(suppl 4S) (abstr 521).

[56] Bujko K, Richter P, Smith FM, Polkowski W, Szczepkowski M, Rutkowski A, et al. Preoperative radiotherapy and local excision of rectal cancer with immediate radical reoperation for poor responders: a prospective multicentre study. Radiother Oncol 2013 Feb;106(2):198-205.

[57] Bujko K, Pietrzak L, Partycki M, Szczepkowski M, Wyrwicz L, Rupiński M, et al. The feasibility of short-course radiotherapy in a watch-and-wait policy for rectal cancer. Acta Oncol 2017 Sep;56(9):1152-4.

[58] Smart CJ, Korsgen S, Hill J, Speake D, Levy B, Steward M, et al. Multicentre study of short-course radiotherapy and transanal endoscopic microsurgery for early rectal cancer. Br J Surg 2016;103:1069-75.

[59] Martens MH, Maas M, Heijnen LA, Lambregts DM, Leijtens JW, Stassen LP, et al Long-term outcome of an organ preservation program after neoadjuvant treatment for rectal cancer. J Natl Cancer Inst 2016;108.

[60] Fisher B, Wolmark N, Rockette H, Redmond C, Deutsch M, Wickerham DL, et al. Postoperative adjuvant chemotherapy or radiation therapy for rectal cancer: results from NSABP protocol R-01. J Natl Cancer Inst 1988 Mar 2;80(1):21-9.

[61] Moertel CG, Fleming TR, Macdonald JS, Haller DG, Laurie JA, Goodman PJ, et al. Levamisole and fluorouracil as adjuvant therapy of resected colon carcinoma. N Engl J Med 1990;322:352-8.

[62] Anon. Efficacy of adjuvant fluorouracil and folinic acid in colon cancer. International Multicentre Pooled Analysis of Colon Cancer Trials (IMPACT) investigators. Lancet 1995:345:939-44.
[63] Petersen SH, Harling H, Kirkeby LT, Wille-Jørgensen P, Mocellin S. Postoperative adjuvant chemotherapy in rectal cancer operated for cure. Cochrane Database Syst Rev 2012 Mar 14;3:CD004078.

[64] Bosset JF, Calais G, Mineur L, Maingon P, Stojanovic-Rundic S, Bensadoun RJ, et al. Fluorouracil-based adjuvant chemotherapy after preoperative chemoradiotherapy in rectal cancer: long-term results of the EORTC 22921 randomised study. Lancet Oncol 2014;15:184-90.

[65] Sainato A, Cernusco Luna Nunzia V, Valentini V, De Paoli A, Maurizi ER, Lupattelli M, et al. No benefit of adjuvant Fluorouracil Leucovorin chemotherapy after neoadjuvant chemoradiotherapy in locally advanced cancer of the rectum (LARC): long term results of a randomized trial (I-CNR-RT). Radiother Oncol 2014;113:223-9.

[66] Breugom AJ, van Gijn W, Muller E, Berglund Å, van den Broek CB, Fokstuen T, et al. Adjuvant chemotherapy for rectal cancer patients treated with preoperative (chemo)radiotherapy and total mesorectal excision: a Dutch colorectal Cancer group (DCCG) randomised phase III trial. Ann Oncol 2015 Apr;26(4):696-701.

[67] Glynne-Jones R, Counsell N, Quirke P, Mortensen N, Maraveyas A, Meadows HM, et al. Chronicle: results of a randomised phase III trial in locally advanced rectal cancer after neoadjuvant chemoradiation randomising postoperative adjuvant capecitabine plus oxaliplatin (XELOX) versus control. Ann Oncol 2014;25:1356-62.

[68] Breugom AJ, Swets M, Bosset JF, Collette L, Sainato A, Cionini L, et al. Adjuvant chemotherapy after preoperative (chemo)radiotherapy and surgery for patients with rectal cancer: a systematic review and meta-analysis of individual patient data. Lancet Oncol 2015 Feb;16(2):200-7.

[69] Hong YS, Nam BH, Kim KP, Kim JE, Park SJ, Park YS, et al. Oxaliplatin, fluorouracil, and leucovorin versus fluorouracil and leucovorin as adjuvant chemotherapy for locally advanced rectal cancer after preoperative chemoradiotherapy (ADORE): an open-label, multicentre, phase 2, randomised controlled trial. Lancet Oncol 2014; 15:1245-53.

[70] Shi $\mathrm{Q}$ Sobrero AF Shields AF, et al. Prospective pooled analysis of six phase III trials investigating duration of adjuvant (adjuv) oxaliplatin-based therapy (3 vs 6 months) for patients (pts) with stage III colon cancer (CC): The IDEA (International Duration Evaluation of Adjuvant chemotherapy) collaboration. J Clin Oncol 2017;35 (suppl; abstr LBA1).

[71] Nilsson PJ, van Etten B, Hospers GA, Påhlman L, van de Velde CJ, Beets-Tan RG, et al. Short-course radiotherapy followed by neo-adjuvant chemotherapy in locally advanced rectal cancer-the RAPIDO trial. BMC Cancer 2013 Jun 7;13:279. https:// doi.org/10.1186/1471-2407-13-279.

[72] McCleary NJ, Meyerhardt JA, Green E, Yothers G, de Gramont A, Van Cutsem E, et al. Impact of age on the efficacy of newer adjuvant therapies in patients with stage II/III colon cancer: findings from the ACCENT database. J Clin Oncol 2013 Jul 10;31(20): 2600-6.

[73] Pieterse AH, Stiggelbout AM, Baas-Thijssen MC, van de Velde CJ, Marijnen CA. Benefit from preoperative radiotherapy in rectal cancer treatment: disease-free patients and oncologists preferences. Br J Cancer 2007;97(6):717-24.

[74] Kennedy ED, Schmocker S, Victor C, Baxter NN, Kim J, Brierley J, et al. Do patients consider preoperative chemoradiation for primary rectal cancer worthwhile? Cancer 2011:117(13):2853-62.

[75] Fried TR, Bradley EH, Towle VR, Allore H. Understanding the treatment preferences of seriously ill patients. N Engl J Med 2002 Apr 4;346(14):1061-6.

[76] Taylor LJ, Nabozny MJ, Steffens NM, Tucholka JL, Brasel KJ, Johnson SK, et al. Schwarze ML.A framework to improve surgeon communication in high-stakes surgical decisions: best case/worst case. JAMA Surg 2017 Jun 1;152(6):531-8.

[77] van Weert JC, van Munster BC, Sanders R, Spijker R, Hooft L, Jansen J. Decision aids to help older people make health decisions: a systematic review and meta-analysis. BMC Med Inform Decis Mak 2016 Apr 21;16:45.

[78] Sanfilippo NJ, Crane CH, Skibber J, Feig B, Abbruzzese JL, Curley S, et al. T4 rectal cancer treated with preoperative chemoradiation to the posterior pelvis followed by multivisceral resection: patterns of failure and limitations of treatment. Int J Radiat Oncol Biol Phys 2001;51:176-83.

[79] Nijkamp J, Kusters M, Beets-Tan RG, Martijn H, Beets GL, Van de Velde CJ, et al. Three-dimensional analysis of recurrence patterns in rectal cancer: the cranial border in hypofractionated preoperative radiotherapy can be lowered. Int J Radiat Oncol Biol Phys 2011;80:103-10.

[80] Syk E, Torkzad MR, Blomqvist L, Nilsson PJ, Glimelius B. Local recurrence in rectal cancer: anatomic localization and effect on radiation target. Int J Radiat Oncol Biol Phys 2008;72:658-64.

[81] Radu C, Berglund A, Pahlman L, Glimelius B. Short course preoperative radiotherapy with delayed surgery in rectal cancer - a retrospective study. Radiother Oncol 2008; 87:343-9.

[82] Markovina S, Youssef F, Roy A, Aggarwal S, Khwaja S, Dewees T, et al. Improved metastasis- and disease-free survival with preoperative sequential short-course radiation therapy and FOLFOX chemotherapy for rectal Cancer compared with neoadjuvant long-course Chemoradiotherapy: results of a matched pair analysis. Int J Radiat Oncol Biol Phys 2017;99:417-26.

[83] Bujko K, Wyrwicz L, Rutkowski A, Malinowska M, Pietrzak L, Kryński J, et al. Longcourse oxaliplatin-based preoperative chemoradiation versus $5 \times 5 \mathrm{~Gy}$ and consolidation chemotherapy for cT4 or fixed cT3 rectal cancer: results of a randomized phase III study. Ann Oncol 2016;27:834-42.

[84] Hupkens BJP, Maas M, Martens MH, van der Sande ME, Lambregts DMJ, Breukink SO, et al. Organ preservation in rectal Cancer after Chemoradiation: should we extend the observation period in patients with a clinical near-complete response? Ann Surg Oncol 2018:25:197-203.

[85] Sun Myint A, Smith FM, Gollins S, Wong H, Rao C, Whitmarsh K, et al. Dose escalation using contact X-ray brachytherapy after external beam radiotherapy as nonsurgical treatment option for rectal Cancer: outcomes from a single-center experience. Int J Radiat Oncol Biol Phys 2018;100:565-73. 
[86] Borstlap WA, Coeymans TJ, Tanis PJ, Marijnen CA, Cunningham C, Bemelman WA et al. Meta-analysis of oncological outcomes after local excision of pT1-2 rectal cancer requiring adjuvant (chemo)radiotherapy or completion surgery. Br J Surg 2016; 103:1105-16.

[87] Tyc-Szczepaniak D, Wyrwicz L, Kepka L, Michalski W, Olszyna-Serementa M, Palucki $\mathrm{J}$, et al. Palliative radiotherapy and chemotherapy instead of surgery in symptomatic rectal cancer with synchronous unresectable metastases: a phase II study. Ann Oncol 2013;24:2829-34

[88] Sprawka A, Pietrzak L, Garmol D, Tyc-Szczepaniak D, Kepka L, Bujko K. Definitive radical external beam radiotherapy for rectal cancer: evaluation of local effectiveness and risk of late small bowel damage. Acta Oncol 2013;52:816-23. 